\title{
DIAGNÓSTICO AMBIENTAL DA UTILIZAÇÃO DA TERRA E DE IMPLICAÇÕES ECOLÓGICAS EM MICROBACIA DA SERRA DO TEIXEIRA, PATOS (PB)
}

\author{
Davi Argemiro Henrique Cardoso de Oliveira ${ }^{1}$ \\ Severina Valéria Gonçalves de Almeida ${ }^{2}$ \\ Veneziano Guedes de Sousa Rêgo ${ }^{3}$ \\ Felipe Silva de Medeiros ${ }^{4}$ \\ Soahd Arruda Rached Farias ${ }^{5}$ \\ Joedla Rodrigues de Lima ${ }^{6}$
}

Resumo: Objetivou-se promover o diagnóstico e prognóstico da ambiência e das prioridades do produtor rural. Utilizou-se do manejo ecológico de bacias hidrográficas. Observou áreas desmatadas, erosões, densidade demográfica e práticas agropecuárias com destaques: revolvimento do solo $(77 \%)$ e aplicação de agrotóxicos (51\%). O percentual de deterioração ambiental foi de $14,49 \%$. Construção de poços (41\%); baixa produção/produtividade (30\%); pouca terra $(30 \%)$ e falta de crédito (26\%) como prioridades dos residentes rurais. Prognosticou implantação de políticas públicas, cooperativas, plano de ação para recuperação de habitats e Educação Ambiental. Concluiu que as atividades rurais influenciaram na redução dos recursos naturais da ambiência.

Palavras-chave: Educação Ambiental; Meio ambiente; Manejo Ecológico; Desenvolvimento Sustentável.

\footnotetext{
1 Universidade Federal de Campina Grande, Patos, Paraíba. E-mail: davicardosod@gmail.com. Link para o Lattes: http://lattes.cnpq.br/7053085272063251

2 Universidade Federal de Campina Grande, Patos, Paraíba. E-mail: valeria.biologicas@gmail.com. Link para o Lattes: http://lattes.cnpq.br/4014048192519147

3 Universidade Federal de Campina Grande, Patos, Paraíba. E-mail: venezianosousa@gmail.com. Link para o Lattes: http://lattes.cnpq.br/3446821344890985

4 Universidade Federal de Campina Grande, Patos, Paraíba. E-mail: fsmedeiros.eng@gmail.com. Link para o Lattes: http://lattes.cnpq.br/6472636047212905

${ }^{5}$ Universidade Federal de Campina Grande, Paraíba. E-mail: soahd.ufcg@gmail.com. Link para o Lattes: http://lattes.cnpq.br/7714562044464927

6 Universidade Federal de Campina Grande, Patos, Paraíba. E-mail: joedlalima@yahoo.com.br. Link para o Lattes: http://lattes.cnpq.br/9739711047450380
} 


\section{Introdução}

As ações antrópicas explorando intensivamente os recursos naturais responde pelo quadro de escassez e deterioração ambiental mundial, notadamente na região Semiárida brasileira.

Tais interferências, pelo seu grau de intensidade, estão alterando o ciclo hidrológico, diminuindo a disponibilidade tanto de água potável, quando do seu volume estocado que atende as necessidades das comunidades urbanas e rurais.

Nesse contexto, a gestão adequada dos recursos hídricos necessita-se de atenção do Poder Público para assessorar o manejo sustentável da bacia hidrográfica. No Brasil, a Política Nacional de Recursos Hídricos (PNRH) estabelecida pela Lei n. 9.433/1997, determina que a bacia hidrográfica é a unidade de planejamento e de gestão de recursos hídricos (BRASIL, 1997).

Segundo Rocha; Kurtz (2001) a bacia hidrográfica é uma região definida por um divisor de águas que retém as chuvas de ravinas, canais e tributários até o fluxo principal.

Mesmo tuteladas pela legislação vigente, as bacias hidrográficas brasileiras têm ampla história de deterioração ambiental. No Nordeste do Brasil a bacia hidrográfica do Rio Piranhas-Açu apresenta importantes destaques. No Estado da Paraíba ela converge os rios Espinharas e Piançó. O Rio Espinharas banha Patos/PB e região metropolitana, formado pelos Rios da Farinha e Rio da Cruz. Já o Rio da Farinha, por sua vez, é represado nas imediações de Patos, dando origem ao maior corpo hídrico, o sistema lêntico Barragem da Farinha.

A Barragem da Farinha retém predominantemente as suas águas do Rio da Farinha, entretanto, possui dois tributários menos expressivos que captam as águas diretamente da Serra do Teixeira. Esse trecho tem relevo fortemente ondulado e se apresenta como área de proteção permanente no Novo Código Florestal do Brasil, Lei 12. 651/2012. Concentra significativa densidade demográfica que acessa e usa os recursos naturais de forma rudimentar, incidindo fortes agravos ao ambiente de serra.

Os efeitos dessa pressão antrópica têm-se mostrado visíveis, ameaçando os recursos primordiais e a economia de forma altamente socializada. Tal situação demanda intervenção do Poder Público e estudos que indiquem formas de recuperação da ambiência deteriorada.

A presente pesquisa se justificou pela barreira cientifica de estudos nesse trecho de drenagem. Outra questão foi a presença de relevo elevado, significativa densidade demográfica, problemas de oferta de recursos hídricos, uso de biodiversidade e indicadores de atividades rurais com pressões humanas de altíssima magnitude.

Partiu-se do questionamento: "estariam as atividades rurais deteriorando os recursos naturais para além da capacidade de suporte da 
natureza"? Nesta perspectiva hipotetizou: "se houver alta possibilidade de redução de recursos naturais e qualidades de vida dependente, então haverá fortes pressões das atividades rurais no meio ambiente".

Assim objetivou-se de forma geral estudar a utilização da terra e implicações ecológicas por meio do diagnóstico e prognóstico da ambiência e prioridades do produtor rural, como contribuição a Educação Ambiental e políticas públicas em desenvolvimento sustentável.

\section{Material e Métodos}

\section{Caracterização da área de estudo}

O Rio da Farinha, pertencente a Sub bacia do Rio Espinharas e integra a bacia hidrográfica do Rio Piranhas - Açu no Estado da Paraíba entre as coordenadas de latitude $7^{\circ} 01^{\prime} 39^{\prime \prime}$ - $7^{\circ} 16^{\prime} 50^{\prime \prime}$ S e longitude $36^{\circ} 43^{\prime} 41^{\prime \prime}-37^{\circ}$ 16 '28' O, conforme apresentado na Figura 1.

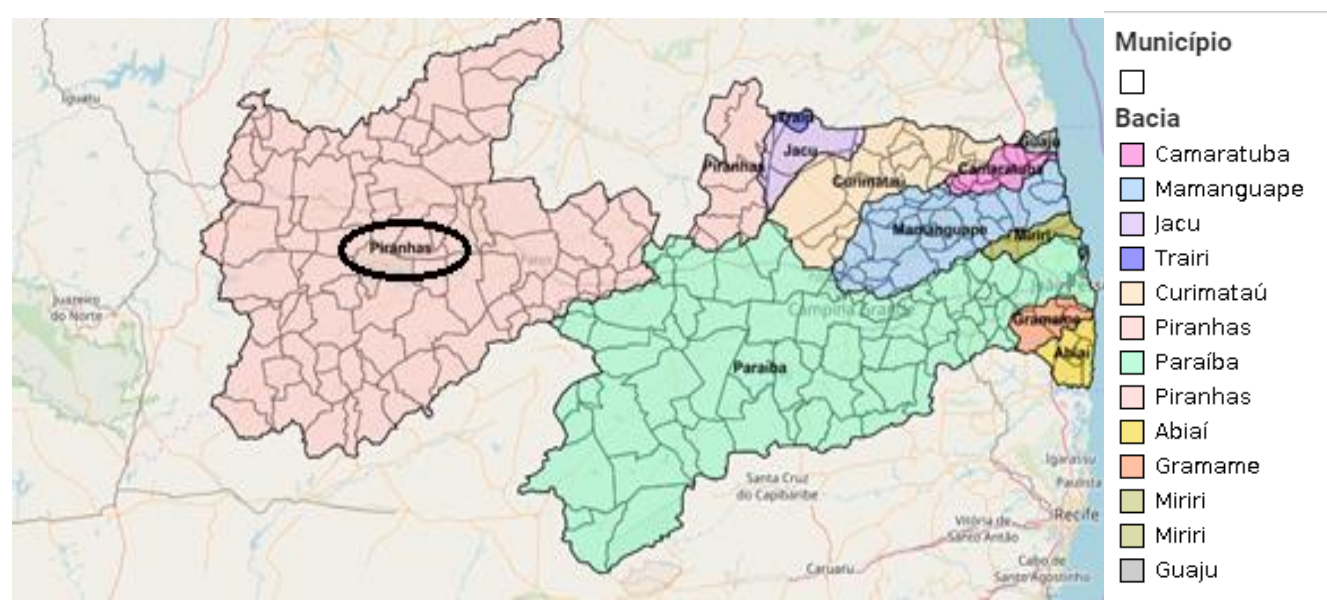

Figura 1: Imagem das Bacias hidrográficas do Estado da Paraíba/Brasil, adaptada com círculo preto para identificar região da Bacia Hidrográfica do Rio Espinharas, Sub bacia Rio da Farinha. Fonte: AESA (2019).

Segundo Guimarães et al., (2017), o Rio da Farinha demonstra paisagem típica do Semiárido nordestino, é caracterizado por clima quente e semiúmido com chuvas de verão - outono. [...] é uma extensa planície, possui relevo suave-ondulado, e afloramentos rochosos (inselbergs), está inserida na "Depressão Sertaneja Setentrional".

O Rio Farinha juntamente com o Rio da Cruz forma o Rio Espinharas nas imediações do centro urbano de Patos/PB.

Para efeito deste estudo foi delimitada uma pequena drenagem que capta diretamente as águas da Serra do Teixeira para uma borda sul da Barragem da Farinha que possui cota de altitude superior ao leito do Rio Farinha. 


\section{Metodologia da pesquisa}

O estudo da utilização da terra e implicações ecológicas por meio do diagnóstico e prognóstico ambiental em trechos de drenagem da Barragem da Farinha, situados na Serra do Teixeira/PB, vinculou variados métodos. Teve ênfase o manejo ecológico de bacias hidrográficas e foco em três eixos principais de análise, a saber: a) conhecer e georreferenciar a área de estudo, b) realizar o diagnóstico ambiental com as prioridades de residentes rurais e c) prognosticar ações rumo a recuperação da ambiência deteriorada.

$\mathrm{Na}$ etapa a) para conhecer e georreferenciar a área de estudo - foram realizadas pesquisas bibliográficas para melhor conhecimento do objeto de estudo. Foram realizadas visitas semanais "in loco". Durante as visitas foram realizadas imagens digitais e utilizado caderno de campo para registrar o contexto mais imediato. Após cada visita foram feitos relatórios para facilitar o detalhamento dos resultados, observando Sousa Rêgo (2010). Para o georreferenciamento e delimitação da área de estudo foram utilizadas imagens do Modelo Digital do Terreno (MDE) da fonte de dados "Shuttle Radar Topography Mission" (SRTM) e softwares disponíveis na Rede mundial de Computadores (QGIS versão 18.2.28/ GRASSGIS/ Google Earth 6.0.2.2014). Foi estabelecido as cotas máximas de altitude automaticamente a partir do exutório da borda sul da barragem para delimitar a microbacia na serra.

$\mathrm{Na}$ etapa b) para realizar o diagnóstico ambiental - foram ponderados o número de propriedades existentes e estabelecido a amostra das residências a serem visitadas, utilizando-se a expressão sugerida por Rocha (1997):

$$
\mathrm{n}=3,841 \times \mathrm{N} \times 0,25 /(0,1)^{2} \times(\mathrm{N}-1)+3,841 \times 0,25,
$$

Em que:

- $\mathrm{n}=$ número de visitas a serem feitas pelo pesquisador;

- 3,841 valor tabelado proveniente do Qui-Quadrado;

- 0,25 é a variância máxima para o desvio padrão de 0,5 ;

- 0,1 é o erro (10\%) escolhido pelo pesquisador;

- N é o número total de casas (moradias) na unidade considerada.

Para o questionário ambiental, foram vinculados o fator ambiental, conforme Sousa Rêgo (2010) e o fator prioritário, conforme Farias et al. (2012).

O fator ambiental foi constituído de 35 indicadores. Para cada indicador foram atribuídos os valores 1, 2 ou 3, respectivamente: valor 1 = não existe a atividade no ambiente; valor 2 = existe atividade no ambiente com orientação técnico-científica; valor $3=$ existe atividade no ambiente sem orientação técnico-científica. O valor 1 indicou a melhor situação (mínimo) e os valores 2 e 3 indicaram a situação mais indesejável (máximo). Para o fator prioridades foram sugeridos 15 problemas mais recorrentes para apoiar a reflexão do residente rural. $\mathrm{O}$ produtor pôde registrar quatro prioridades, ordenadamente 
da primeira até a quarta (podendo ser as prioridades indicadas ou novas prioridades por ele avaliadas).

Foram realizadas as entrevistas com os produtores rurais voluntários, a partir da assinatura do Termo de Consentimento Livre e Esclarecido. O projeto foi submetido ao Comitê de Ética localizado no Hospital Universitário Alcides Carneiro da Universidade Federal de Campina Grande.

Após as entrevistas e a coleta das informações via observação participante, foram tabulados os dados em planilhas eletrônicas sendo considerado para cada indicador (código) do fator ambiental o valor mais frequente, ou seja, a moda.

Para a determinação do percentual de deterioração $(Y)$, usou-se a equação da reta com base em Rocha (1997):

$$
\mathrm{Y}=\mathrm{ax}+\mathrm{b}
$$

Em que:

- $Y=$ Unidade crítica de deterioração ambiental (\%);

- $a$ e b = São coeficientes;

- $\mathrm{X}=$ Resultado da soma das modas obtidas.

O valor de $Y(\%)$ pôde variar de 0 a $100 \%$ de deterioração. Segundo Rocha (1997) valores acima de 10\% demandam intervenções humanas para favorecer a integridade dos processos ecológicos comprometidos.

O Diagnóstico Ambiental (fator ambiental + fator prioridade), por sua vez, consistiu em levantar e analisar os principais elementos da poluição direta, ações antrópicas impactantes e as prioridades emergentes dos produtores rurais.

$\mathrm{Na}$ etapa $\mathrm{C}$ ) para prognosticar ações rumo a recuperação da ambiência deteriorada, foram geradas sugestões de medidas corretivas a partir dos principais diagnósticos detectados durante as etapas "a" e "b".

\section{Resultados e discussão}

Com o protocolo do Certificado de apresentação para Apreciação Ética (CAAE): 96311018.0 .0000 .5182 a pesquisa foi aprovada pelo Comitê de Ética em Pesquisa do Hospital Alcides Carneiro da Universidade Federal de Campina Grande.

Verificou-se que a metodologia foi eficiente no diagnóstico de interações socioeconômicas e ambientais relacionadas a utilização da terra e implicações na área de drenagem da Barragem da Farinha situada na Serra do Teixeira/PB. 


\section{Conhecimento e georreferenciamento da área de estudo}

Foram realizadas cinco visitas de campo, entre novembro/2018 e janeiro/2019 para reconhecimento "in loco" dos problemas socioambientais no entorno das propriedades da região de estudo e coleta de dados com os proprietários rurais.

Verificou-se na macropaisagem natural propriedades, estradas, recursos hídricos e líderes das comunidades que foi decisivo para a coleta de informações relevantes.

Foram observados açudes não conhecidos pelo Autor: o Açude Novo que fica após a Barragem da Farinha na vila conhecida como Vila da Fumaça, o Açude do Totó e o Riacho do Cambo que deságuam no Rio da Farinha, Barragem da Farinha.

No Sítio Liberdade ocorreu diálogo com o Presidente da Associação de Agricultores local, que articulou os contatos para as entrevistas com os seus associados.

Foi verificado que o trecho de serra possui relevo elevado, afloramentos rochosos, vegetação de Caatinga, várzea nos locais baixos, riqueza em biodiversidade e serviços ecossistêmicos (provisão, regulação, culturais), apresentado abaixo na Figura 2.

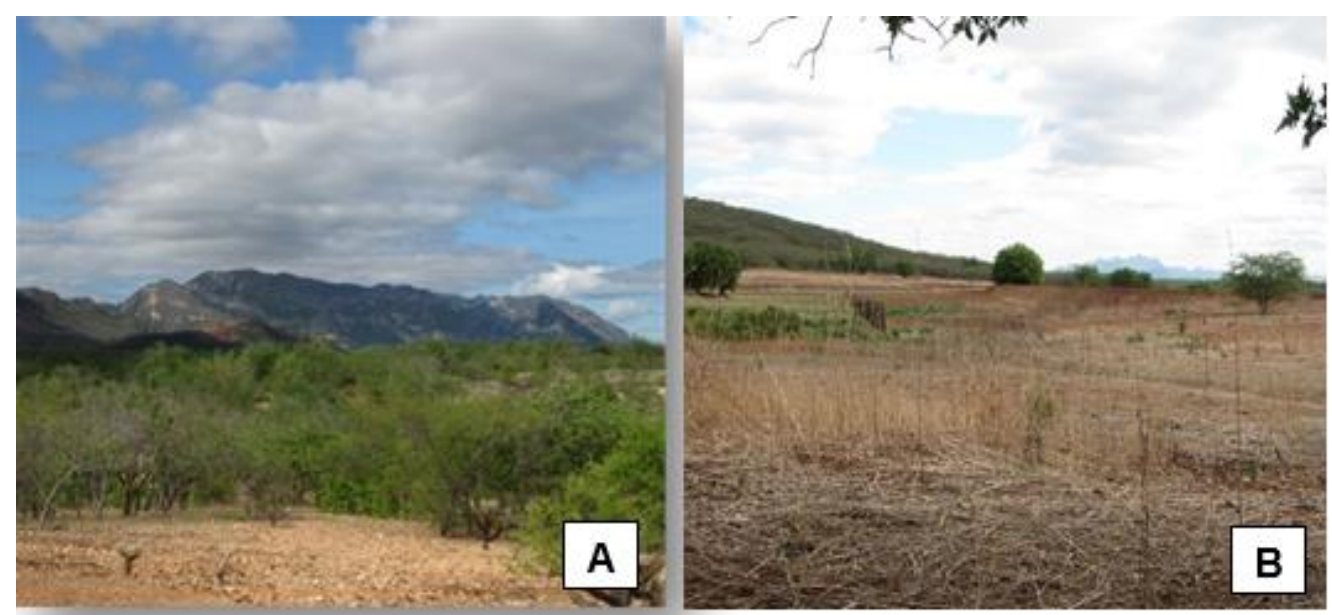

Figura 2: Em "A" e "B" mosaico de imagens identificando aspectos da paisagem em trecho da Serra do Teixeira/PB drenado diretamente para a Barragem da Farinha.

Fonte: autores (2019).

Foi possível observar áreas desmatadas, erosões e razoável densidade demográfica no entorno da Barragem da Farinha com presença de práticas agropecuárias e fortes indícios de pressões impactantes.

Ficou constatada a presença de resíduos sólidos urbanos em diversos trechos de acesso as áreas de drenagem, adjacências das propriedades rurais e entorno da barragem, configurando problema socioambiental recorrente, apresentado Figura 3. 

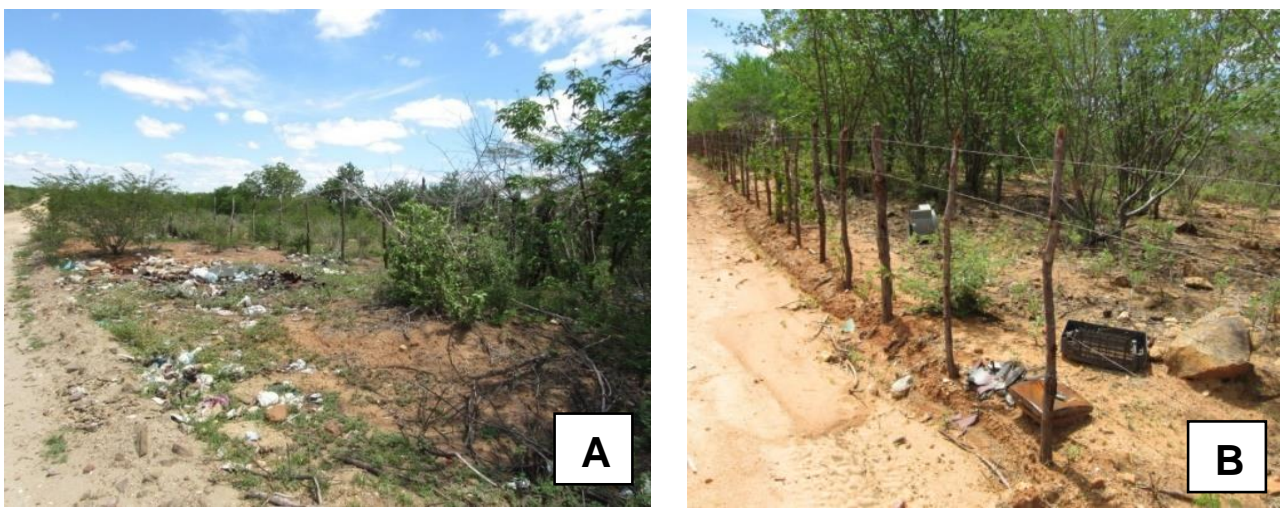

Figura 3: Em "A" e "B" mosaico de imagens identificando presença de resíduos sólidos urbanos dispersos (sentido Serra do Teixeira Barragem da Farinha, Patos/PB).

Fonte: autores (2019).

O descarte inadequado de resíduos sólidos urbanos continua sendo um severo problema de saúde coletiva no Brasil. Tais resíduos lançados a "céu aberto" se tornam potenciais poluentes de corpos hídricos e do solo, podendo contaminar os ecossistemas próximos.

Pôde-se deduzir que essa realidade comum pouco avançou no Brasil, mesmo após a criação da Política Nacional de Resíduos Sólidos (PNRS), por meio da Lei Federal № 12.305 de 02 de agosto de 2010. A PNRS estabelece responsabilidade à toda sociedade na gestão integrada e gerenciamento de resíduos sólidos, entendendo que a sua destinação final precisa ser ambientalmente adequada.

\begin{abstract}
"Estão sujeitas à observância desta Lei as pessoas físicas ou jurídicas, de direito público ou privado, responsáveis, direta ou indiretamente, pela geração de resíduos sólidos e as que desenvolvam ações relacionadas à gestão integrada ou ao gerenciamento de resíduos sólidos" ( $\S 1^{\circ}$ art. $1^{\circ}$ PNRS, BRASIL, 2010 p1.).
\end{abstract}

Outro fato observado e que mereceu atenção foi o cultivo de hortaliças, que se constitui como uma atividade agrícola predominante na região, conforme apresentada na Figura 4.

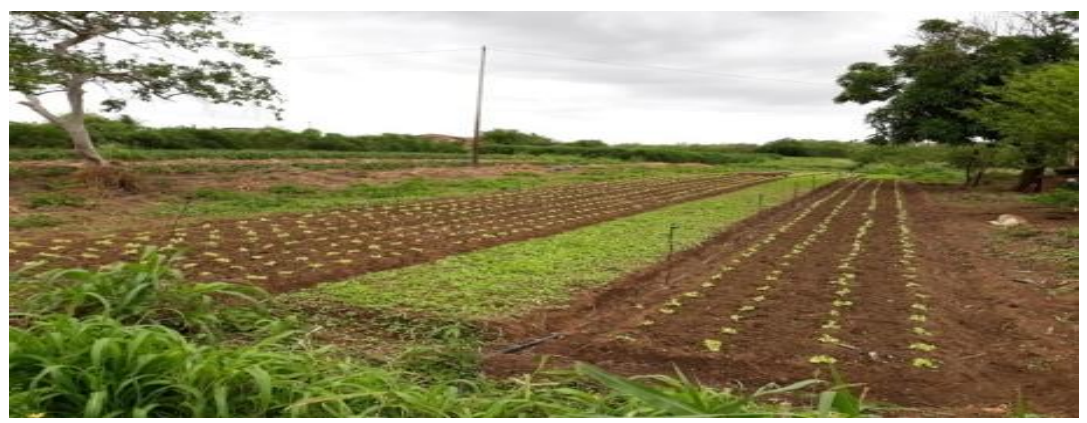

Figura 4: Cultivo de hortaliças no entorno da Barragem da Farinha.

Fonte: autores (2019).

Revbea, São Paulo, V. 14, № 4: 170-184, 2019. 
Os plantios tradicionais tendem a ser atacados com maior frequência por pragas e demanda largo uso de químicos tóxicos. O excesso de agroquímicos pode ser carreado para o interior da barragem e alterar os parâmetros físicos, químicos e bióticos dos ecossistemas aquáticos.

Segundo Dias (2009) a destinação dos resíduos fisicoquímicos profana o ambiente. Corrobora Sánchez (2008, p. 24), afirmando que "a poluição suja a natureza, profanando os processos naturais da ambiência".

Nesta perspectiva tem-se a transição para a agroecologia como uma excelente opção para o desenvolvimento da região.

O georreferenciamento da área de estudo balizou o trecho especial de microbacia que capta as águas diretamente da Serra do Teixeira para a Barragem da Farinha nas coordenadas geográficas de longitude UTM $690.000 \mathrm{~m}$ E e latitude $9.205 .000 \mathrm{~m}$ S, descritos na Figura 5.

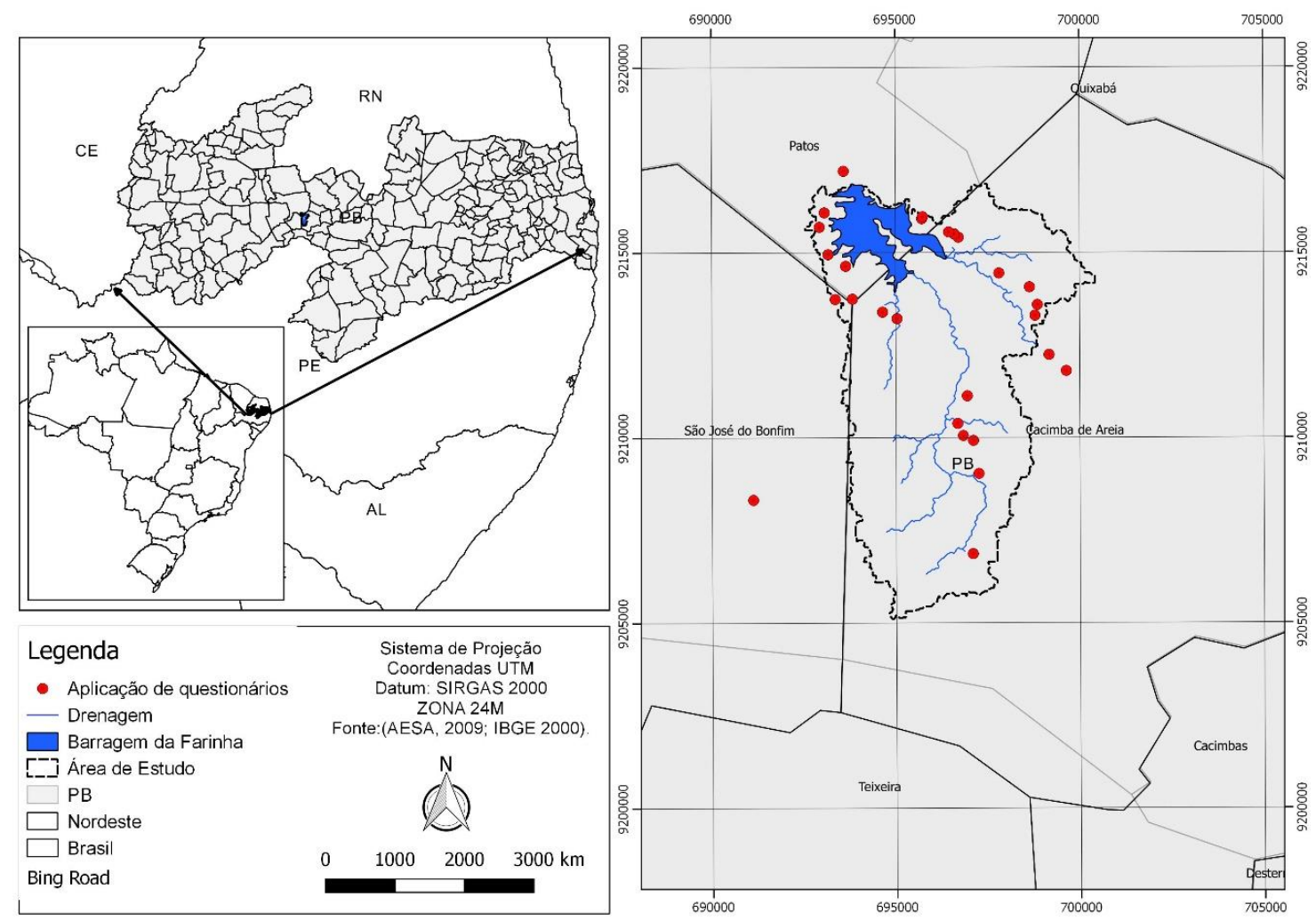

Figura 5: Mapa da delimitação da área de estudo (Barragem da Farinha, Estado da Paraíba, Brasil, e pequeno trecho de microbacia que nasce na Serra do Teixeira, sentido Cidade do Teixeira), adaptado com pontos vermelhos para identificar os locais de aplicação dos questionários.

Fonte: autores (2019).

A área total da microbacia hidrográfica foi calculada em 53,9 quilômetros quadrado e perímetro de 47 quilômetros. 


\section{Diagnóstico ambiental}

Ponderou 41 residências ou propriedades na área de estudo através do reconhecimento "in loco". A margem amostral indicou 27 propriedades para a aplicação dos questionários semiestruturados, com base em Rocha (1997).

Foi verificado na ambiência a predominância de essências florísticas nativas da caatinga nos trechos de nascente (serra) e espécimes introduzidas pelo homem com atividades agropecuárias modificadoras da paisagem natural (no entorno da barragem).

Revolvimento do solo (77\%) e aplicação de agrotóxicos (51\%) foram as práticas desenvolvidas pelos residentes ou proprietários rurais que tiveram o maior percentual de citações, conforme apresentado na Tabela 1.

Tabela 1: Percentual decrescente de indicadores do diagnóstico ambiental envolvendo práticas agrícolas no trecho da Serra do Teixeira drenado para a Barragem da Farinha, Patos/PB.

\begin{tabular}{|c|c|}
\hline Indicadores & $\%$ \\
\hline Revolvimento expressivo do solo & 77 \\
\hline Erosões marcantes no terreno ou em vias de tráfego & 66 \\
\hline Aplicação de agrotóxicos & 51 \\
\hline Bombas de recalques de água & 51 \\
\hline Redução de habitats e da biodiversidade & 48 \\
\hline Locais de lavagem de implementos de aplicação dos agrotóxicos & 40 \\
\hline Uso de EPIs para aplicação de agroquímicos & 40 \\
\hline Destino das embalagens de defensivos & 37 \\
\hline Presença de matadouros & 33 \\
\hline Estocagem de defensivos & 29 \\
\hline Presença de pocilgas & 29 \\
\hline Assoreamento de corpos hídricos & 26 \\
\hline Total & 100 \\
\hline
\end{tabular}

Fonte: autores (2019).

Avaliou frente a realidade observada que se faz urgente a adoção de políticas públicas e a capacitação dos produtores da região.

Ações educativas de órgãos públicos competentes orientados para a segurança em atividades rurais insalubres é urgente, a exemplo da necessidade de uso de equipamentos de proteção individual - EPI para a aplicação de agrotóxicos, conforme a Lei no 6,514 de 22 de dezembro de 1977 e a Norma Regulamentadora de № 6). 
Já o manejo para a estocagem dos defensivos agrícolas, o destino das embalagens de defensivo e os locais para lavagem de implementos de aplicação dos agrotóxicos, devem ser adequados e corretos, observando a Lei no 7.802 , de 11 de julho de 1989 e o Decreto oㅜ 4. 074, de 4 de janeiro de 2002.

O percentual de deterioração ambiental foi $14,49 \%$ obtido por meio da unidade crítica de deterioração ambiental, apresentado na Tabela 2.

Tabela 2: Deterioração ambiental encontrada no trecho da Serra do Teixeira drenado para a Barragem da Farinha - microbacia hidrográfica do Rio Farinha.

\begin{tabular}{|c|c|c|c|c|c|c|c|}
\hline \multirow[b]{2}{*}{$\begin{array}{c}\text { Diagnóstico } \\
\text { ambiental }\end{array}$} & \multicolumn{3}{|c|}{$\begin{array}{l}\text { Soma dos valores mínimo } \\
\text { e máximo - } 35 \text { indicadores } \\
\text { ambientais (questionário) }\end{array}$} & \multicolumn{3}{|c|}{$\begin{array}{l}\text { Equação da reta } \\
\qquad(\mathrm{Y}=\mathrm{aX}+\mathrm{b})\end{array}$} & \multirow{2}{*}{$\begin{array}{c}\text { Deterioração } \\
\text { Ambiental } \\
\mathrm{Y}=(\%)\end{array}$} \\
\hline & Mínimo & Máximo & $\begin{array}{l}\text { Moda } \\
\text { geral } \\
(X)\end{array}$ & $\begin{array}{c}\text { Valores } \\
\text { de a }\end{array}$ & & $\begin{array}{c}\text { Valores } \\
\text { de b }\end{array}$ & \\
\hline $\begin{array}{c}\text { Unidade } \\
\text { crítica de } \\
\text { deterioração } \\
\text { ambiental }\end{array}$ & 35 & 105 & 45 & 1,449 &.$X$ & $-50,00$ & 14,49 \\
\hline
\end{tabular}

Fonte: autores (2019).

Verificou-se que $14,49 \%$ representa valor acima do limite estabelecido por Rocha (1997), cujo percentual de deterioração máximo é de $10 \%$, observado na Figura 6.

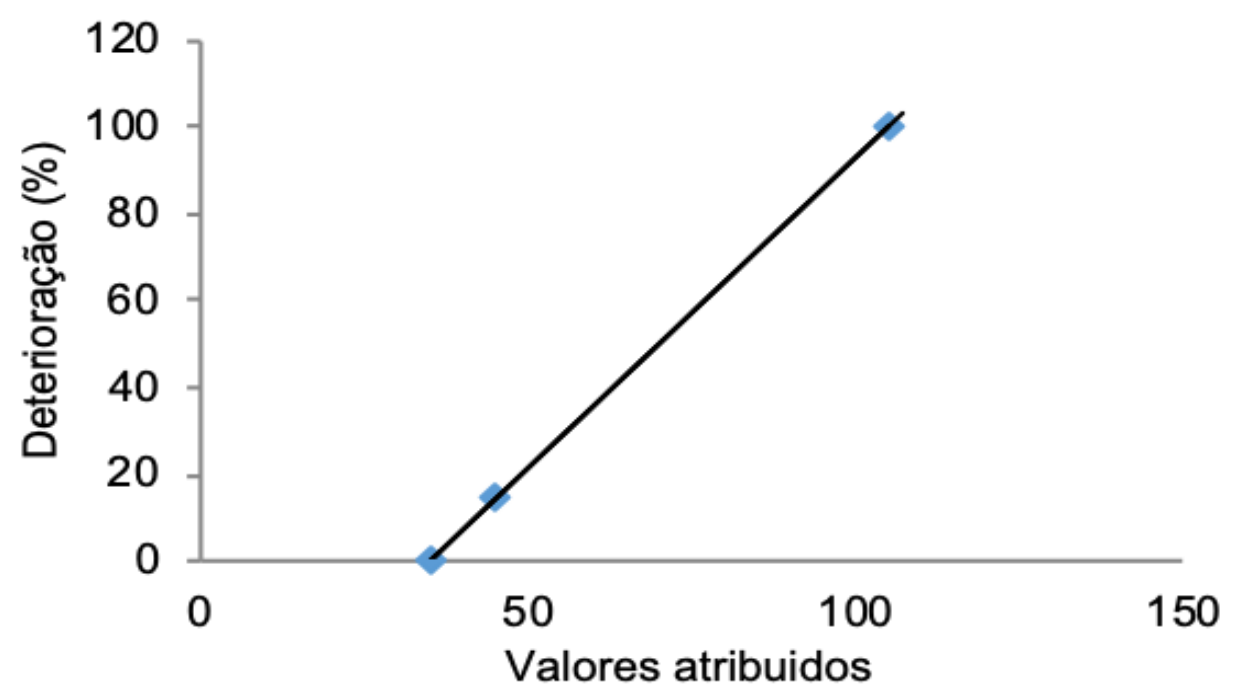

Figura 6: Gráfico da Reta da deterioração ambiental do trecho Serra do Teixeira drenado para a Barragem da Farinha.

Fonte: autores (2019). 
Nesta perspectiva se pôde inferir que existe a necessidade da intervenção humana para se combater de forma eficaz a magnitude da deterioração da ambiência ponderada para a região.

Diferentes trabalhos publicaram resultados de percentuais de deterioração bem maiores que o aqui encontrado, revelando regiões que ainda sofrem intenso impacto ambiental, a exemplo da pesquisa de Baracuhy (2001) na Microbacia Paus Brancos, Queimadas/PB que indicou a deterioração ambiental de 33,34\%; Sousa Rêgo (2010) na Microbacia Riacho das Piabas, Campina Grande/PB, obteve 42,86\%; Alves et al., (2011), na Microbacia Rio do Saco, Santa Luzia/PB, 41,38\%; Silva e Mattos (2013) Microbacia Riacho do Poço de Serra, Currais Novos/RN, registrou 20,00\%; Costa e Silva et al., (2017), Microbacia Riacho do Trapiá, Currais Novos, RN - 30,00\%.

Dentre os fatores prioritários citados pelos residentes e/ou proprietários rurais para a melhoria da qualidade de vida, teve destaques: fazer um poço $(41 \%)$; baixa produção/produtividade (30\%); pouca terra (30\%): falta de crédito (26\%), conforme apresentado na Tabela 3 e Figura 7.

Tabela 3: Frequência das respostas das prioridades citadas pelos residentes e/ou proprietários rurais (trecho da Serra do Teixeira drenado para a Barragem da Farinha) e suas respectivas ordens.

\begin{tabular}{|c|c|c|c|c|c|}
\hline Frequência das respostas & $\begin{array}{l}\text { PROBLEMAS PRIORITÁRIOS CITADOS } \\
\text { PELOS ENTREVISTADOS }\end{array}$ & $\begin{array}{l}\bar{\varepsilon} \\
\frac{\varepsilon}{d} \\
\overline{0}\end{array}$ & $\begin{array}{l}N \\
\frac{1}{d} \\
\text { o } \\
\text { Oे }\end{array}$ & $\begin{array}{c}m \\
\frac{c}{0} \\
\frac{0}{0} \\
\overline{0}\end{array}$ & 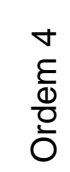 \\
\hline 11 & 16 - Fazer um poço & 7 & 1 & 1 & 2 \\
\hline 8 & 3 - Baixa produção/produtividade & 0 & 4 & 3 & 1 \\
\hline 7 & 2 - Pouca terra & 2 & 5 & 0 & 0 \\
\hline 7 & 9 - Falta de crédito & 1 & 0 & 2 & 4 \\
\hline 6 & 12 - Estradas (ruins - falta) & 0 & 2 & 0 & 4 \\
\hline 5 & 4 - Falta de água & 1 & 0 & 2 & 2 \\
\hline 5 & 7 - Falta de assistência médica e odontológica & 1 & 1 & 2 & 1 \\
\hline 5 & 8 - Falta de boa habitação & 0 & 2 & 2 & 1 \\
\hline 5 & 10 - Falta de mercado & 0 & 1 & 1 & 3 \\
\hline 5 & 17 - Construir um açude & 2 & 0 & 3 & 0 \\
\hline
\end{tabular}

Fonte: autores (2019). 


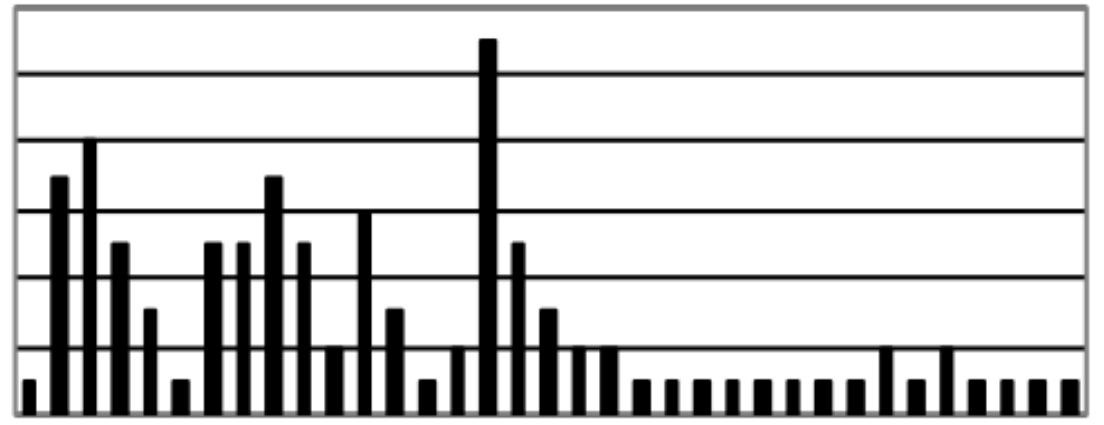

\section{Prioridades dos ruralistas}

Figura 7: Gráfico das prioridades para os residentes do trecho da Serra do Teixeira drenado para a Barragem da Farinha.

Fonte: autores (2019).

Avaliou-se que os altos valores estão diretamente ligados a utilização das práticas agrícolas desassistidas por políticas públicas, desprovidas de orientação técnica adequada e em desacordo com os padrões ecológicos locais.

Pôde verificar que existem fortes pressões das atividades rurais no trecho de microbacia drenado da Serra do Teixeira para a Barragem da Farinha e redução dos recursos naturais e como também qualidade de vida dependente.

\section{Prognósticos}

Vinculando conhecimento e georreferenciamento da área de estudo ao diagnóstico ambiental propriamente dito (fator ambiental e fator prioridades) foi possível elaborar 15 prognósticos gerais como sugestão de ações para a recuperação da ambiência deteriorada:

- Fortalecimento do papel da Associação de Agricultores e apoio à formação de novas cooperativas locais de base sustentável como diferencial ao desenvolvimento socioeconômico dos proprietários rurais e região;

- Promoção do Cadastro Ambiental Rural (CAR) para disciplinar as áreas de proteção permanente e reserva legal, levando ao produtor informação para manter os ecossistemas frágeis, recuperar habitats e diversidade biológica que melhore ao mesmo tempo a qualidade de vida local;

- Reflorestamento das áreas desmatadas não destinadas as atividades rurais e combate a erosões.

- Valorização do saneamento ambiental na região observando a legislação vigente;

- Apoio à produção orgânica de hortifrutigranjeiros na região; 
- Avaliação constante da qualidade da água da barragem e de pequenos corpos hídricos adjacentes, observando possibilidade de contaminação por agroquímicos;

- Valorização da cobertura verde nativa e redução dos espécimes exóticos.

- Combate as erosões que carreiam o solo fértil e apelo pelo não revolvimento do solo, exceto nas boas práticas como adubação orgânica;

- Redução do uso de agrotóxicos, utilização de regras e de equipamentos de segurança e destino correto das embalagens de agrotóxicos;

- Acesso dos habitats com parcimônia observando proteger a biodiversidade;

- Planejamento de ações conjuntas entre proprietários rurais e o Poder Público pela recuperação da ambiência deteriorada;

- Adoção de políticas públicas e fortalecimento dos processos em Educação Ambiental para capacitação dos produtores em prol do "desenvolvimento sustentável" para a região.

- Focalização de esforços para atender as prioridades dos residentes que reclamam por recursos hídricos, melhoria da produtividade e crédito.

- Orientação para práticas agrícolas sustentáveis e fomento para a transição do modelo atual para a base agroecológica.

- Valorização da visão sistêmica na agropecuária e a utilização de ciência e tecnologias alinhadas com a sustentabilidade socioambiental.

\section{Considerações Finais}

O trecho de microbacia hidrográfica da Serra do Teixeira drenado diretamente para a Barragem da Farinha e posteriormente para o Rio Farinha possui 53,9 quilômetros quadrado e perímetro de 47 quilômetros.

Existem na macropaisagem propriedades, práticas agropecuárias, estradas, recursos hídricos, relevo elevado, afloramentos rochosos, vegetação de caatinga, várzea nos baixios, riqueza em biodiversidade e serviços ecossistêmicos.

Há razoável densidade demográfica, áreas desmatadas, erosões, resíduos "a céu aberto" e próximos a corpos hídricos à revelia da legislação ambiental.

O cultivo de hortaliças usa agrotóxicos e se configurou como a atividade agrícola predominante.

O ruralista está descuidado das regras de segurança e do uso de EPI's.

As práticas agrícolas estão desassistidas por políticas públicas, desprovidas de orientação técnica e inadequadas a manutenção dos padrões ecológicos locais.

Faz-se urgente políticas públicas para educação e capacitação dos produtores rumo à modelos de "desenvolvimento sustentável" para a região.

A unidade crítica de deterioração ambiental (14,49\%) acima do limite 
Ações conjuntas entre Poder Público e proprietários rurais são fundamentais para melhoria da qualidade de vida local.

$\mathrm{O}$ atendimento das prioridades dos residentes a exemplo da carência de recursos hídricos e a baixa produtividade, o fomento de políticas educativas de capacitação dos residentes; o fortalecimento das associações/cooperativas, a promoção do Cadastro Ambiental Rural (CAR), o reflorestamento das áreas desmatadas, a promoção do saneamento ambiental alternativo, o apoio a produção orgânica e a avaliação da qualidade das águas são os maiores obstáculos.

Há necessidade de crédito rural para transição do modelo agropecuário tradicional para modelos agropecuários de base ecológica.

Urge a necessidade cientifica e tecnológica de atenuar as limitações ao desenvolvimento local observando a visão sistêmica e a sustentabilidade ambiental.

Existem fortes pressões das atividades rurais reduzindo progressivamente os recursos naturais do meio ambiente.

Sugere-se novos estudos que observem a dinâmica da ecosocioeconômia local em termos de causas e efeitos dos desequilíbrios e as melhores estratégias educativas e socioeconômicas de desenvolvimento durável.

\section{Referências}

ALVES. J. B. Impactos ambientais e delimitação da área de preservação permanente do Rio Espinharas no trecho urbano de Patos-PB. Redes (St. Cruz Sul, Online), v. 21, n 2, p. 107 - 130, maio/ago. 2016. Disponível em: <http://dx.doi.org/10.17058/redes.v21i2.7248>. Acessado em: maio de 2018.

ALVES, T. L. B.; ARAÚJO, A. R.; ALVES, A. N.; FERREIRA, A. C.; NÓBREGA, J. E. Diagnóstico ambiental da Microbacia Hidrográfica Rio do Saco, Santa Luzia - PB. Revista Brasileira de Geografia Física, v. 4, n. 2, p. $396-4012$, 2011.

BARACUHY, J. G. V. Manejo integrado de microbacias no Semiárido nordestino: estudo de um caso. 2001. 297 f. Tese (Doutorado em Recursos Naturais) - Universidade Federal de Campina Grande, Campina Grande. 2001.

BRASIL. Constituição da República Federativa do Brasil de 1988. Presidência da República. Planalto. Brasília. [Recurso eletrônico]. Disponível em: <http://www.planalto.gov.br/ccivil03/Constituicao/Constituicao.htm>. Acessado em fevereiro de 2019.

BRASIL. Decreto no 4.074, de 4 de janeiro de 2002 que regulamenta a lei no 7.802, de 11 de julho de 1989. Disponível em: $<$ http://www.planalto.gov.br/ccivil 03/decreto/2002/d4074.htm>. Acessado em: fevereiro de 2019. 
BRASIL. Política Nacional de Recursos Hídricos. Lei o 9.433 de 8 de janeiro de 1997. Disponível em: <http://www.planalto.gov.br/ccivil03/leis/l 9433.htm>. Acessado em: janeiro de 2019.

COSTA E SILVA, D.; BARACUHY, J.; CURI, W. F.; CUNHA, T. P. S. Diagnóstico socioeconômico e ambiental em uma área susceptível a desertificação: estudo de caso da microbacia Riacho do Trapiá - Rio Grande do Norte - Brasil. Revista Espacios, v. 38, n. 03, p. 18, 2017.

DIAS, R. Gestão Ambiental: responsabilidade social e sustentabilidade. São Paulo: Atlas, 2009. 196 p.

FARIAS et al. Gestão de bacias hidrográficas. In: ROCHA, A.P.T.et al.(Orgs.). Manejo ecológico integrado de bacias hidrográficas no semiárido brasileiro. EPGRAF, 2012. $511 \mathrm{P}$.

IBGE - INSTITUTO BRASILEIRO DE GEOGRAFIA E ESTATÍSTICA. Panorama, 2017. Disponível em: <https://cidades.ibge.gov.br/brasil/pe/itapetim/ panorama>. Acessado em: maio 2018.

ROCHA, J. S. M. Manual de manejo integrado de bacias hidrográficas. Santa Maria: Universidade Federal de Santa Maria. Centro de Ciências Rurais. 2.ed, 181 p. 1991. Disponível em: <https://www.bdpa.cnptia.embrapa.br/>. Acessado em: maio de 2018.

SILVA, R. M. P.; J. R.; LIMA et al. Alteração da cobertura vegetal na Sub-Bacia do Rio Espinharas de 2000 a 2010. Revista Brasileira de Engenharia Agrícola e Ambiental: v.18, n.2, p. $202-209,2014$.

SILVA, D. D. C.; MATTOS, A. Diagnóstico socioeconômico e ambiental em Microbacia Hidrográfica localizada em um núcleo de desertificação. Caminhos de Geografia, v. 14, n. 45, p. $45-53,2013$.

SOUSA RÊGO, V. G. Diagnóstico e prognóstico socioeconômico e ambiental das nascentes do Riacho das Piabas (PB). 2010. 125 f. Dissertação (mestrado) - Centro de Tecnologia e Recursos Naturais, Universidade Federal de Campina Grande, Campina Grande. 2010. Disponível em: $<$ http://www.recursosnaturais.ufcg.edu.br/downloads/venezianoguedesde sousa.pdf>. Acessado em: maio 2018. 